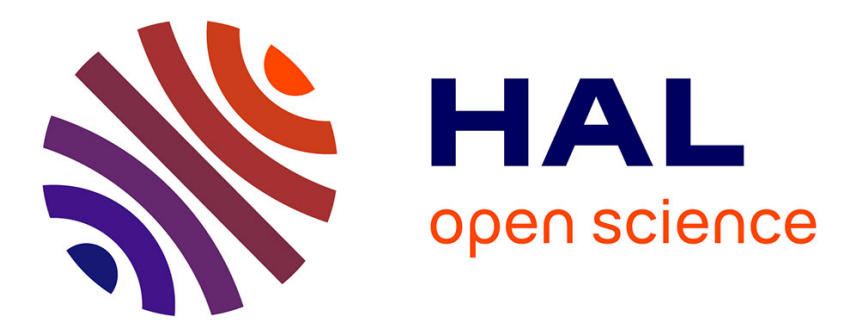

\title{
Cortical Activity Prior to, and During, Observation and Execution of Sequential Finger Movements
}

\author{
Claire Calmels, Paul Holmes, Gilbert Jarry, Jean-Michel Lévêque, Magaly
}

Hars, Cornelis J Stam

\section{To cite this version:}

Claire Calmels, Paul Holmes, Gilbert Jarry, Jean-Michel Lévêque, Magaly Hars, et al.. Cortical Activity Prior to, and During, Observation and Execution of Sequential Finger Movements. Brain Topography: a Journal of Cerebral Function and Dynamics, 2006, 19 (1-2), pp.77-88. 10.1007/s10548006-0014-x . hal-01576059

\section{HAL Id: hal-01576059 https://hal-insep.archives-ouvertes.fr/hal-01576059}

Submitted on 22 Aug 2017

HAL is a multi-disciplinary open access archive for the deposit and dissemination of scientific research documents, whether they are published or not. The documents may come from teaching and research institutions in France or abroad, or from public or private research centers.
L'archive ouverte pluridisciplinaire HAL, est destinée au dépôt et à la diffusion de documents scientifiques de niveau recherche, publiés ou non, émanant des établissements d'enseignement et de recherche français ou étrangers, des laboratoires publics ou privés. 


\title{
Cortical Activity Prior to, and During, Observation and Execution of Sequential Finger Movements
}

\author{
Claire Calmels, ${ }^{*, I l}$ Paul Holmes, ${ }^{\dagger}$ Gilbert Jarry, ${ }^{\ddagger}$ Jean-Michel Lévèque, ${ }^{*}$ \\ Magaly Hars, ${ }^{*}$, and Cornelis J. Stam ${ }^{\mathscr{S}}$
}

\begin{abstract}
Summary: The aim of this study was to provide further evidence for the existence of a mirror neuron system in humans using electroencephalography during the observation and execution of non-object-related movements. Event-related desynchronization and synchronization (ERD/ERS) were used to characterize brain activity prior to, and during, observation and execution of a finger movement in four frequency bands (7-10 Hz, 10-13 $\mathrm{Hz}, 13-20 \mathrm{~Hz}$, and $20-30 \mathrm{~Hz}$ ). Electroencephalograms (EEGs) were recorded from 19 electrode sites in eight participants. In all the frequency bands and electrode sites, results revealed that there was no significant differences in EEG cortical activity between the observation condition and the execution conditions. Comparison of the two stages of the movement (i.e., pre-movement and movement) in the observation and execution conditions showed, in most cases, that pre-movement ERD values were less than movement ERD values. Whilst there was not an identical match of EEG cortical indices, this study provides further support for the existence of a mirror neuron system in humans. The incomplete congruence may be explained by the different behaviors, the nature of the task and factors in the observed action coded by the mirror system.
\end{abstract}

Key words: Electroencephalography; Mirror neurons; Event-related de/synchronization; Non-object-related action.

\section{Introduction}

Mirror neurons were first discovered in the ventral premotor cortex of the macaque monkey (Rizzolatti et al. 1988). These neurons were shown to fire when the animal executed a goal-directed hand movement (Rizzolatti et al. 1988) and also when it observed the same action performed by another monkey or by a human (e.g., Gallese et al. 1996). These findings support the proposal that mirror neurons form the basis of an observation-execution matching system (Iacoboni et al. 1999; Muthukumaraswamy et al. 2004; Rizzolatti et al. 2001). This system has also been called the motor resonance system or the mirror neuron system.

Evidence for the existence of a matching system in humans has also been provided (see Buccino et al.

\footnotetext{
* Institut National du Sport et de l'Éducation Physique, Paris, France.

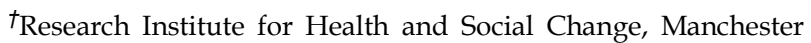
Metropolitan University, UK.

¥Hôpital Henri Mondor, Créteil, France.

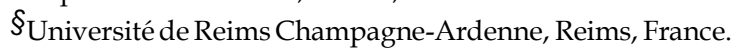

"Department of Clinical Neurophysiology, VU University Medical Centre, Amsterdam, The Netherlands.

Accepted for publication: September 26, 2006; Published Online: November 292006.

ICorrespondence and reprint requests should be addressed to Claire Calmels, Département des Sciences du Sport, Institut National du Sport et de l'Éducation Physique, 11 Avenue du Tremblay, 75012 Paris, France. E-mail: claire.calmels@insep.fr.

Copyright Q 2006 Springer Science + Business Media, Inc.
}

2004a; Rizzolatti and Craighero 2004 for a review). In humans, this system acts differently depending upon the forms of observed motor behaviours. Viewing a grasping action performed by a non-biological model involved the observation-execution matching system but was less effective than watching the same action executed by another human (Perani et al. 2001; Tai et al. 2004). Mimicking actions without objects (e.g., biting an apple, kicking a ball, performing a grip of a manipulandum) elicited motor resonance (Buccino et al. 2001; Muthukumaraswamy et al. 2004). For example, Muthukumaraswamy et al. (2004) have shown that the 8-13 $\mathrm{Hz}$ rhythm generated by the sensorimotor cortex was desynchronized during the observation of an object grip and, to a lesser extent, during the observation of an empty grip. Biologically impossible movements (Stevens et al. 2000) and actions that did not belong to the behavioural repertoire of the individuals (Buccino et al. 2004b) did not activate the observation-execution matching system.

Research has shown that the human motor resonance system is also activated by the observation of non-object-related actions. Observing with the purpose of later imitation and executing the lifting of a finger has shown, with functional magnetic resonance imaging (fMRI), activations in premotor and posterior parietal cortex; these are areas known to possess mirror properties (Iacoboni et al. 1999). Using transcranial magnetic stimulation (TMS), Maeda et al. (2002), for thumb and 
index finger opposition and Patuzzo et al. (2003) for flexion and extension movement performed by the fingers of the right hand, have detected changes in motor corticospinal excitability induced by the observation of these actions. These changes, specific to the muscles involved in the movement, have been proposed to be generated by the observation-execution matching system (Fadiga et al. 1995). Interestingly, the instructions provided to the participants were goal focused. Maeda et al. (2002) required the participants to only attend to the movements displayed on the video screen and Patuzzo et al. (2003) required the participants not to imitate the observed movement at a later stage. Observation instructions may be important to the profile of the recorded neural activity.

Electroencephalographic (EEG) studies have also shown a similar pattern in EEG data during the observation and execution of non-goal directed finger movements. For example, Cochin et al. (1999) found comparable changes in EEG spectral power during the observation and execution of thumb and index finger opposition in the $7.5-10.5 \mathrm{~Hz}, 18-25 \mathrm{~Hz}$, and $25-35 \mathrm{~Hz}$ bands. Babiloni et al. (2002) also showed similar alpha and beta synchronization and desynchronization in scalp regions over premotor and primary sensorimotor cortex during observation and execution of fast finger extension movements. The participants in Cochin et al.'s (1999) study were required to observe the movement with no specific goal. In contrast, Babiloni et al.'s (2002) participants were told to avoid using motor imagery during executed and observed movements. More recently, Calmels et al. (2006) also found no significant difference in synchronization likelihood (i.e., a non-linear index of synchronization between distant neuronal population; seeStam and van Dijk 2002) during observation and performance of sequential finger movements. These different methods (i.e., fMRI, TMS, EEG) have shown that non-goal directed actions activated the mirror neuron system in humans. This characteristic, which is not developed in the monkey's system, should be of prime importance to the process of imitation in humans (Rizzolatti and Craighero 2004). Humans seem to possess a motor resonance system that is able to code the details of the observed action. This system allows them to reproduce the observed action (Rizzolatti 2005).

More recently, this characteristic has been questioned by Jackson et al. (2006). They showed that observation of non-goal directed movements did not involve the premotor cortex (i.e., ventral premotor cortex, the inferior frontal gyrus), an area known to be associated with mirror properties. This result, which does not support previous literature, suggests that Broca's area (Brodmann areas 44 and 45) is not active during the observation of non-goal directed action. However, it was activated during the delayed execution of a task (e.g.,
Makuuchi 2005) and the left inferior frontal gyrus was active during tasks which require selection (Zhang et al. 2004).

EEG studies have used two analysis techniques to provide evidence of a human mirror system irrespective of the nature of the observed action: power spectrum analysis (Cochin et al. 1999; Muthukumaraswamy and Johnson 2004; Muthukumaraswamy et al. 2004); and event-related change of EEG activity (Babiloni et al. 2002). Whilst both approaches provide an index of cortical activity, power spectrum analysis has, traditionally, been the most common method to analyze the raw EEG signal (Blinowska and Durka 2001; Duhamel and Vetterli 1990).

Event-related changes of EEG activity in a given frequency band are markers that have typically been used to characterize brain activity and which retain temporal information. This analysis procedure has been studied extensively by Pfurtscheller and colleagues (e.g., Pfurtscheller and Aranibar 1977; Pfurtscheller and Lopes da Silva 1999). In the context of movement planning, change in power in a frequency band was defined as a change relative to a baseline period recorded a few seconds before the occurrence of the event. A decrease of relative power is termed event-related desynchronization (ERD) and an increase is termed event-related synchronization (ERS). Quantification of ERD/ERS is made in the time domain. Research that has considered ERD/ERS patterns of voluntary movements has tended to examine fast finger movements. The durations of these movements are generally less than 500 ms (e.g., Derambure et al. 1999; Pfurtscheller et al. 1996; Pfurtscheller et al. 1998) and only two or three electrodes sites have been considered (e.g., Pfurtscheller et al. 1998). Consideration of longer duration movements, and through a full electrode montage, is therefore of interest; especially since everyday life actions tend to be greater than $500 \mathrm{~ms}$.

Since Jackson et al. (2006) have questioned the involvement of the mirror neuron system during the observation and execution of non-object-related actions, the aim of the present study was to provide additional evidence for such activity in humans. Long duration, sequential finger movements were chosen since their control represents an essential skill within the human motor system. This behavior is involved in a broad range of activities, for example: playing the piano; keyboard typing; and performing microsurgical operations (Gerloff and Hallett 1999). Further, Zhuang et al. (1997) have suggested that this movement pattern has been insufficiently studied. To our knowledge, no EEG studies have examined cortical activity during the observation and execution of non-object-related actions where the instructions are to reproduce the observed actions at a later stage. Examination of this issue should refine the knowledge of the mirror neuron system. 
It was hypothesized that the brain oscillations underlying the observation of a sequential finger movement would show similarities to those identified in the physical execution of the same movement in frequency bands lying within a range of 7-30 Hz. Pre-movement phase was also considered within this frequency range for both conditions.

\section{Method}

Participants

Eight individuals (mean age $=23$ years, $\mathrm{SD}=3.2$ ), with no neurological or psychiatric conditions participated in the study. All individuals provided written informed consent. The study was approved by the local ethics committee (Comité Consultatif de Protection des Personnes dans la Recherche Biomédicale, CCPPRB). All participants were assessed as right-handed by the Edinburgh Handedness Inventory (Oldfield 1971). Participants were not informed of the goals of the study as the tacit knowledge of the aims and procedures may have influenced their behaviour during the experimentation.

Task

The participants were required to perform a finger movement sequence. This consisted of a flexion followed by an extension of the right forefinger to create an angle of 90 degrees between the distal and medial phalange whilst the hand remained in a supine position. The movement was repeated twice at a rate of $2 \mathrm{~Hz}$ and lasted 2 sec.

\section{Experimental Procedure}

The participants were examined in two conditions; action observation and action execution. The order of assessment was the same for each participant. Observation assessment was performed first as participants were required to replicate it at a later stage. Multichan- nel EEG was recorded whilst participants sat in a darkened room with their arms lying on the armrests. To reduce eye movement and other electromyographic artifacts throughout the EEG data collection, participants were asked to avoid blinking by fixing their attention on a target point placed on a screen situated $1.30 \mathrm{~m}$ in front of them, to keep their jaw tension free, and generally to be relaxed. These instructions were provided prior to each set of trials.

A metronome, set at $2 \mathrm{~Hz}$, imposed temporal consistency and similar experimental parameters in the execution and observation conditions (Manganotti et al. 1998). It also ensured a similar number of flexions and extensions per trial across conditions and participants.

\section{Action Observation Condition}

Participant performed 40 trials for the observation task. Each trial comprised three stages presented to the participant via a video display. Instructions were provided to the participants requiring them to observe the movement with the intention of repeating it at a later stage. Participants were also instructed not to move their fingers during the three stages of the trial.

During the first four second stage of each trial the participant observed an amber monitor screen warning the participant of the imminent requirement to move. During the second stage, lasting two seconds, participants observed a video of a human model performing a finger movement sequence at $2 \mathrm{~Hz}$. In the third stage, lasting six seconds, the modeled finger movement finished and a red background was presented requiring the participant to relax (see Figure 1). The time interval between the beginning of viewing the movement and the onset of the next trial was $12 \mathrm{sec}$. During the action observation condition, the experimenter controlled that the fingers were not moved.

\section{Action Execution Condition}

Each participant physically performed 40 trials of the task following a similar procedure to the observation

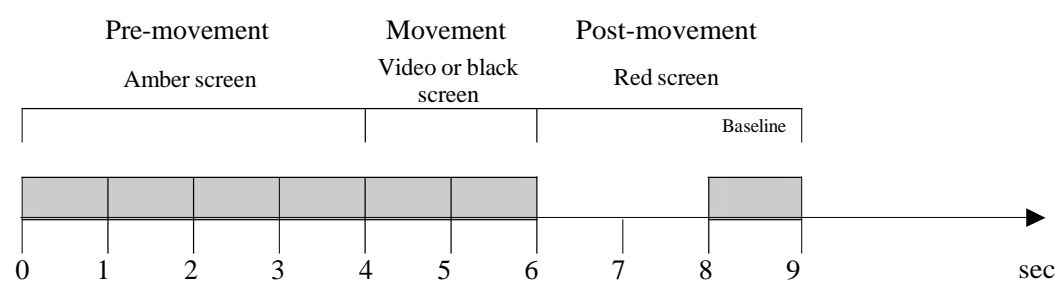

Figure 1. Schema for one trial to be analyzed off-line irrespective of condition. Shaded sections were used for EEG analysis. 
trials. The first stage warned the participant about the imminent movement requirement. In the second, a black background was presented to the participant. During this stage he/she performed the finger movement at 2 $\mathrm{Hz}$. In the third stage, a red background prompted the participant to stop the movement and relax. The procedure is represented in Figure 1. The time interval between the beginning of one movement and the onset of the next was $12 \mathrm{sec}$. During the action execution condition, the experimenter checked the accuracy of the movements performed by the participants.

All trials were triggered using a photoresistive diode that responded to the screen color change. Two, eight-minute blocks of 40 trials were performed. Each block was separated by a five minute rest period. The first block was the action observation block and the second, action execution.

\section{Data Acquisition and Recording}

Electrical brain activity was recorded from 19Ag/ AgCl pad electrodes (Fp1, Fp2, Fz, F7, F8, F3, F4, Cz, C3, C4, PZ, P3, P4, T3, T4, T5, T6, O1, and O2) held on the head with a rubber cap and placed in accordance with the international 10-20 system (Jasper, 1958). Mastoids were used for the reference electrodes and the ground electrode was located on the forehead. Electrooculograms (EOG) were also registered from the canthi of both eyes (horizontal EOG) and the supra and infra orbital of the right eye (vertical EOG). Electrode impedance was kept homogenously below $5 \mathrm{kQ}$ throughout the experimentation and was checked systematically between the two blocks of trials. Amplifier bandwidth was set between 0.15 and $114 \mathrm{~Hz}$ using a computer-based EEG recorder (Coherence, Deltamed, Paris, France). Baseline-corrected activity was sampled at $256 \mathrm{~Hz}$. AD resolution was 16 bit.

\section{Data Processing}

In the present study, EEG data were analyzed by the ERD/ERS computation technique (Pfurtscheller and Aranibar 1977; Pfurtscheller and Lopes Da Silva 1999). This was performed in four different frequency bands (i.e., 7-10 Hz; $10-13 \mathrm{~Hz} ; 13-20 \mathrm{~Hz}$; and $20-30 \mathrm{~Hz}$ ). The choice of the band widths was based on previous research which has shown that these frequency bands were particularly reactive to the planning and the execution of finger movements in cortical oscillatory activity in humans (e.g., Andres et al. 1999; Classen et al. 1998; Cochin et al. 1999; Sterman et al. 1994). The first step of the data processing was off-line segmentation of EEG trials.

\section{Segmentation of EEG Trials}

40 trials were completed during the eight-minute condition. Each trial was subdivided into 3 stages. For the action observation condition, the stages were $4 \mathrm{sec}$ prior to the onset of the observation of movement until the onset of the observation, the 2 sec of the observation of movement, and the $6 \mathrm{sec}$ after the movement. The same principle was applied to the action condition. Off-line analysis of the third stage revealed that eye movement artifacts contaminated the data in the final three seconds of some trials. Consequently, this stage was reduced to $3 \mathrm{sec}$ in length and the last second of this three-second stage served as the baseline reading (see Figure 1). This period was chosen as an appropriate reference as there was no meaningful stimulus input. Participants were instructed to relax and to rest whilst viewing the red screen. Four stages were distinguished within a trial after the off-line analysis: the premovement stage ( $0-4 \mathrm{sec})$; the movement stage ( $4-6 \mathrm{sec})$; the post-movement stage $(6-8 \mathrm{sec})$; and the baseline (8-9 sec) (see Figure 1).

\section{ERD/ERS Computation (Pfurtscheller and Aranibar 1977; Pfurtscheller and Lopes Da Silva 1999)}

EEG trials were inspected for artifacts. Trials with ocular and muscular artifacts were discarded from further analysis. The band power method (Pfurtscheller and Aranibar 1977; Pfurtscheller and Lopes Da Silva 1999) was used to quantify ERD/ERS in the time domain. Raw EEG signals of all artifact-free trials were bandpass filtered. The band pass filter was zero phase. The filtered values were squared to obtain power values which were averaged across all artifact-free trials. Change in power within a particular frequency band was determined as a percentage measurement: $E R D \%=(A-R) / R \times 100$. $(R$ is defined as a reference period and $\mathrm{A}$ as a test period). A negative ERD designates a power decrease (desynchronization), whereas a positive ERD indicates a power increase (synchronization) (see Pfurtscheller and Aranibar 1977; Pfurtscheller and Lopes Da Silva 1999 for further details).

Computation of the ERD/ERS was performed with Neuroscan 4.1 software (Revision A 1999) on each of the four frequency bands and on each electrode site during observation and execution for each participant. The following options were selected: band power; bandpass filter in a centered symmetric frequency band with a rolloff of $48 \mathrm{~dB}$ / octave; envelope; reference interval with a start of $8000 \mathrm{~ms}$ and a stop of $9000 \mathrm{~ms}$; percent decrease scaling; averaging window span to $125 \mathrm{~ms}$ with the collapse option; and ERD/ERS mixture for the phase locking. 
This included phase-locked and non-phase-locked activity and approximated to the sum of the induced and evoked activity. For each participant, and each electrode site, 48 power values (one every $125 \mathrm{~ms}$ ) were obtained for each of the four frequency bands during observation and execution.

\section{Statistical Analysis}

All statistical analyses were performed using Statistica (1997). Changes in power were analyzed using non-parametric tests; the Wilcoxon matched-paired signed rank test (e.g., Derambure et al. 1999) and the Mann-Whitney $U$ test. Non-parametric tests were used since the homogeneity of the variance, monitored with Levene's test, was not validated. First, a Wilcoxon matched-paired signed rank test was undertaken to evaluate the statistical differences of power values in the observation and execution conditions for each electrode site and each frequency band. All ERD or ERS value, obtained in a particular $125 \mathrm{~ms}$ interval and for a specific electrode under the observation condition were compared to the ERD or ERS value obtained in the same $125 \mathrm{~ms}$ interval and for the same electrode but under the execution condition. Due to the repeated testing, a Bonferroni correction was used to correct the Type-1 error. Significance level were rectified providing an alpha level of $p<.001$.

Secondly, a unilateral Mann-Whitney $U$ test was completed to assess whether pre-movement ERD/ERS values were significantly different from movement ERD/ERS values. This was performed for the 19 electrode sites, in each frequency band, and under observation and execution conditions. The $32125 \mathrm{~ms}$ time periods of the pre-movement were compared to the $16125 \mathrm{~ms}$ time periods of the movement. A Bonferroni correction was used with an alpha level of $p<.0025$.

\section{Results}

We have presented the statistically significant differences and the trends towards significance because the Bonferroni correction is known to provide an overly conservative correction (Burgess and Gruzelier 1999). Weiss and Rappelsberger (2000) have argued that the Bonferroni correction leads to extremely low thresholds that makes it difficult to reject the null hypothesis because of the large number of variables. Therefore, any possible effects could be rejected. It is also worth noting that most of the published EEG studies, using repeated testing, did not correct Type-1 errors (Burgess and Gruzelier 1999).

\section{Comparison of Power Values in the Observation and Execution Conditions}

48 Wilcoxon tests were computed for each electrode to compare the power values in the observation and execution conditions in a same $125 \mathrm{~ms}$ interval.

For all the frequency bands, no significant differences between observation and execution were found for any $125 \mathrm{~ms}$ time period (i.e., for the pre-movement and movement stages).

For the $10-13 \mathrm{~Hz}$ band, the Wilcoxon test revealed a trend towards significance between observation and execution for some $125 \mathrm{~ms}$ periods. Negative power decreases during observation were less than the negative power decreases during execution for FP1, F3, C4, C3, $\mathrm{T} 6$, and $\mathrm{Fz}$ (see Figure 2). The same trend was found in the $20-30 \mathrm{~Hz}$ band at FP2, F4, C4, C3, Fz, and Cz (see Figure 3).

\section{Comparison of Pre-movement Power Values and Movement Power Values}

Mann-Whitney $U$ tests were computed for the 19 electrode sites for each frequency band to assess the ERD/ERS statistical significance between the premovement stage and the movement stage.

In the observation condition, significant differences between the pre-movement and movement stages were found in: the 7-10 Hz band (except for $\mathrm{O} 1$ and PZ electrode sites); the 10-13 Hz band (except for FP2, F8, F4, C3, FZ and CZ electrode sites); the 13-20 Hz band (except for F8, F7, T4, T5, and T6 electrode sites); and the 20-30 Hz band (except for FP2, FP1, F8, F7, F4, T4, T3, C4, C3, T5, FZ, CZ, and PZ electrode sites) (see Figure 4). In the execution condition, significant differences between the pre-movement and movement stages were found in: the 7-10 Hz band (except for FP1, F4, F3, T4, O1, and FZ electrode sites); the $10-13 \mathrm{~Hz}$ band; the $13-20 \mathrm{~Hz}$ band (except for F8 and T4 electrode sites); and the 20$30 \mathrm{~Hz}$ band (except for F7,T3, and T5 electrode sites) (see Figure 4).

The Mann-Whitney $U$ test also indicated a trend towards significance between the pre-movement and the movement stages for some scalp locations in the observation and execution conditions. These locations have been identified by a white square on Figure 4 . For both conditions, pre-movement ERD values were less than the movement ERD values (see Table I).

\section{Discussion}

The aim of the present study was to provide additional evidence for the existence of a mirror neuron system in humans during observation and execution of non-object-related actions. EEG activity prior to and 
FPI

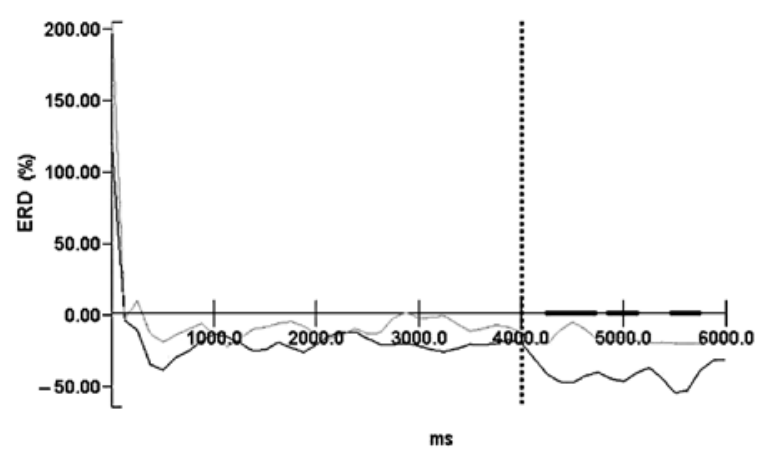

F3

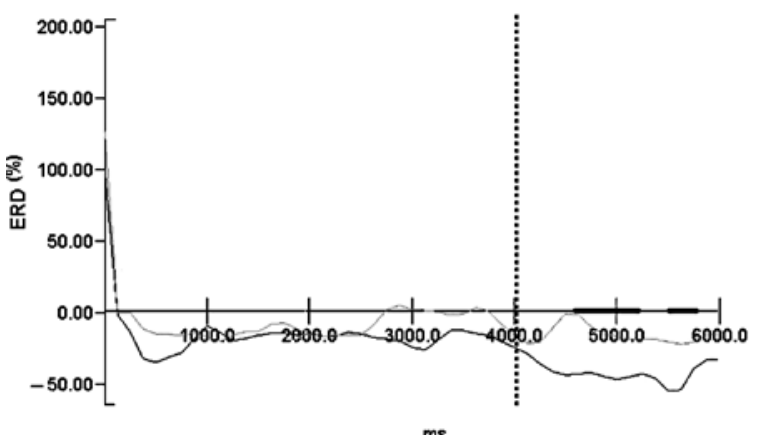

C4

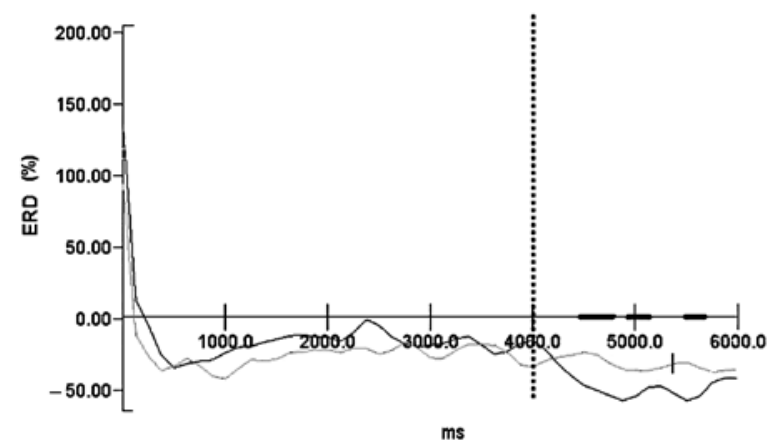

C3

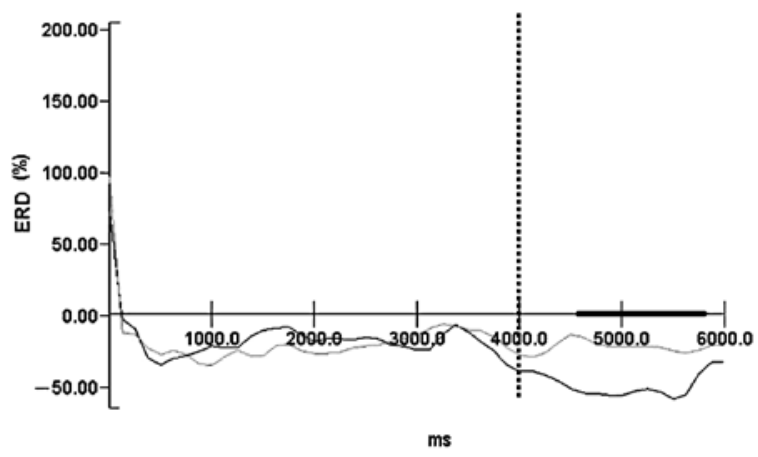

T6

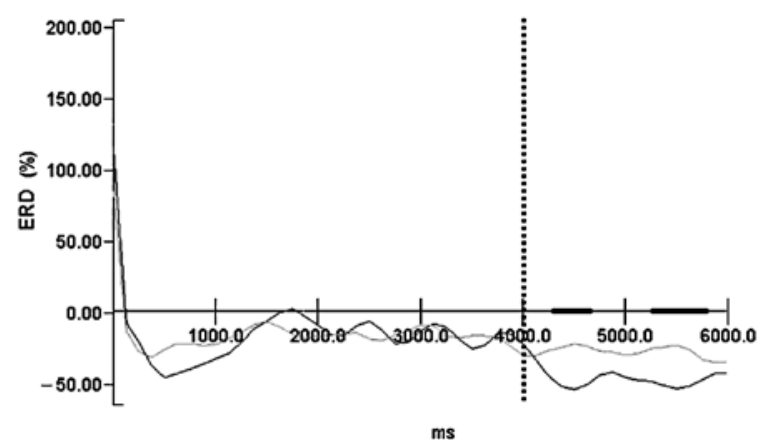

$\mathrm{Fz}$

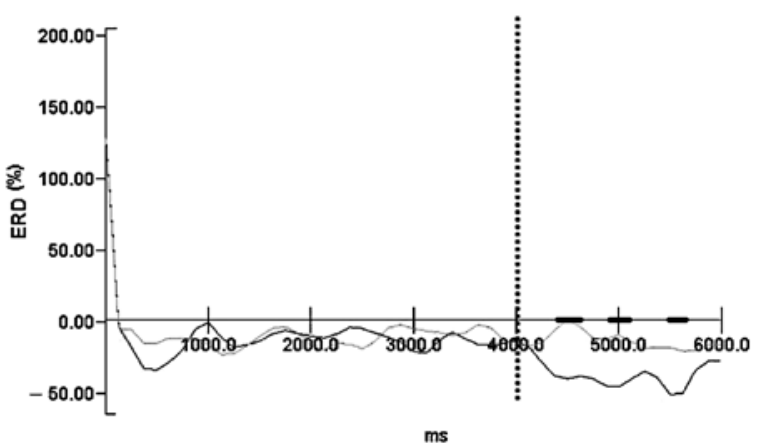

Figure 2. Superimposed time course of ERD in the 10-13 Hz frequency band for FPI , F3, C4, C3, T6, and Fz electrodes and for all the participants. Black lines correspond to execution, whereas grey lines represent observation. Trends towards significant changes are indicated by black bars above the $x$-axis. Movement onset is indicated by a dashed vertical line at time $4000 \mathrm{~ms}$.

during the physical execution of a finger movement was compared with that prior to and during the observation of the same movement in the 7-30 Hz frequency band via the ERD/ERS computation technique. As the results are compared with research that has not always used the same data analysis procedures and that did not consider exactly the same frequency bands, interpretation of our results should be made with some caution. The term 'synchronization' has been used in the literature with varied definitions. This has the potential for confusion. One definition has been the mechanism for integrating and representing information in the brain. Different brain regions communicate via a process where large groups of neurons fire in synchrony (e.g., Varela et al. 2001). Therefore it is a marker of the coupling between two different brain areas and is derived from measures of correlation between the two signals. A second meaning is that used by Pfurtscheller's research group, and which has been frequently used in the psychophysiology literature and which has been adopted in this study. Synchronization here is inferred from specific band power changes. Consequently, these changes cannot be interpreted in terms of changes in coupling in the underlying network. 
FP2

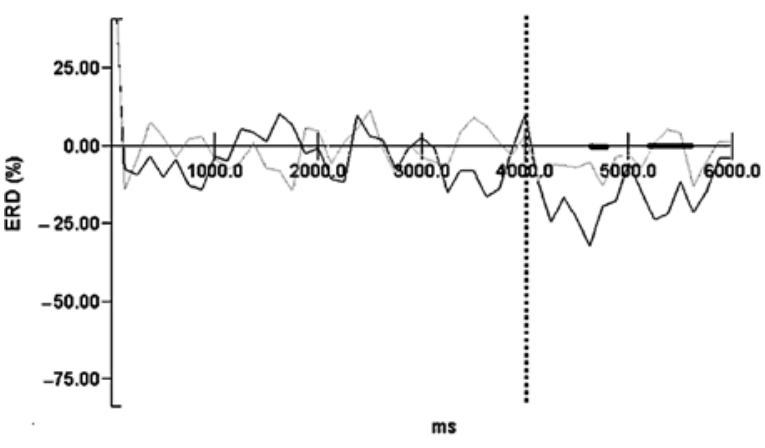

F4

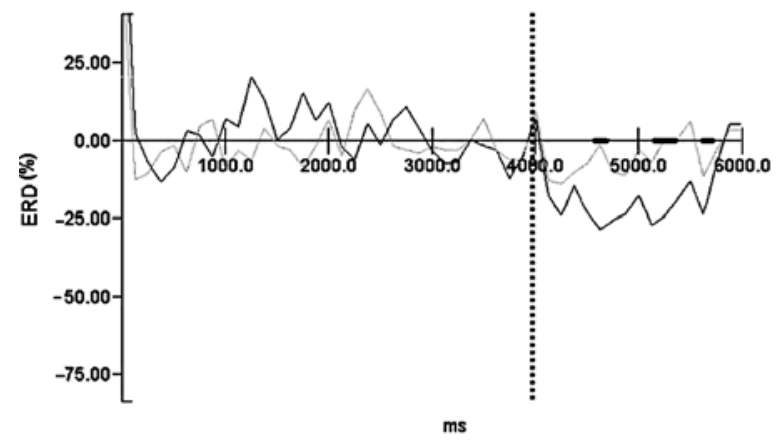

C4

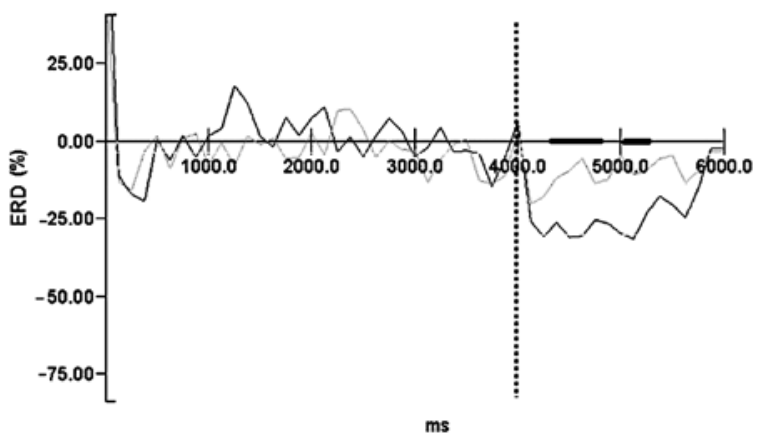

C3

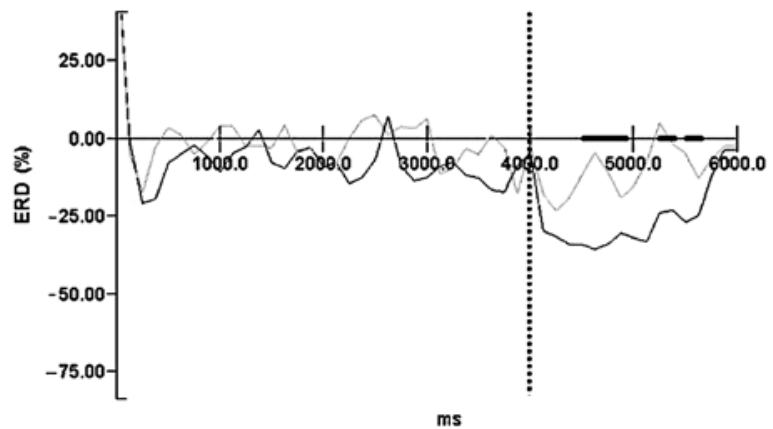

$\mathrm{Fz}$

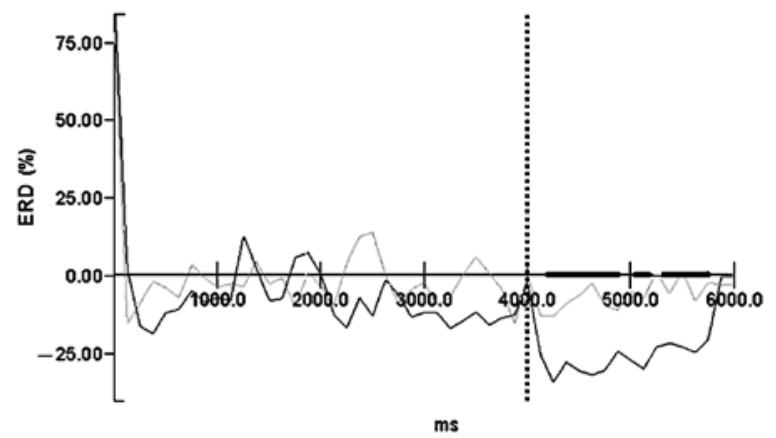

$\mathrm{Cz}$

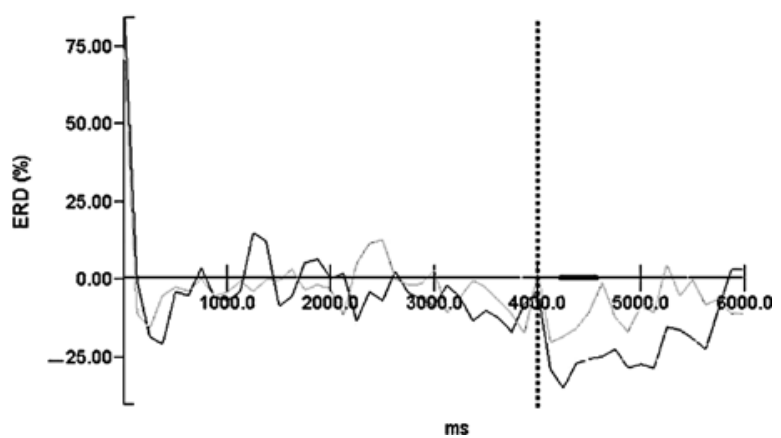

Figure 3. Superimposed time course of ERD in the 20-30 Hz frequency band for FP2, F4, C4, C3, Fz, and Cz electrodes and for all the participants. Black lines correspond to execution, whereas grey lines represent observation. Trends towards significant changes are indicated by black bars above the x-axis. Movement onset is indicated by a dashed vertical line at time $4000 \mathrm{~ms}$.

The discussion has been organized into three sections. The first discusses the ERD/ERS power results between the observation and execution conditions. The second considers the ERD/ERS power values between the pre-movement and movement stages. The third reviews critically the limitations of the study.

\section{Observation and Execution Conditions}

There was no significant difference in ERD/ERS power values between the observation and execution data during the pre-movement stage for all frequency bands; a finding consistent with Kilner et al. (2004) who showed the presence of a readiness potential, an electrophysiological markers of motor preparation, prior to the observation of an action. No significant differences were found between observation and execution during the movement stage for all frequency bands. These results are, for example, in line with those of Cochin et al. (1999) who showed equivalence in logarithmic spectral power during the observation and execution of finger movements for $7.5-10 \mathrm{~Hz}, 18-25 \mathrm{~Hz}$, and $25-35 \mathrm{~Hz}$ bands.

The results also support those of Calmels et al. (2006). In that study, the authors investigated 

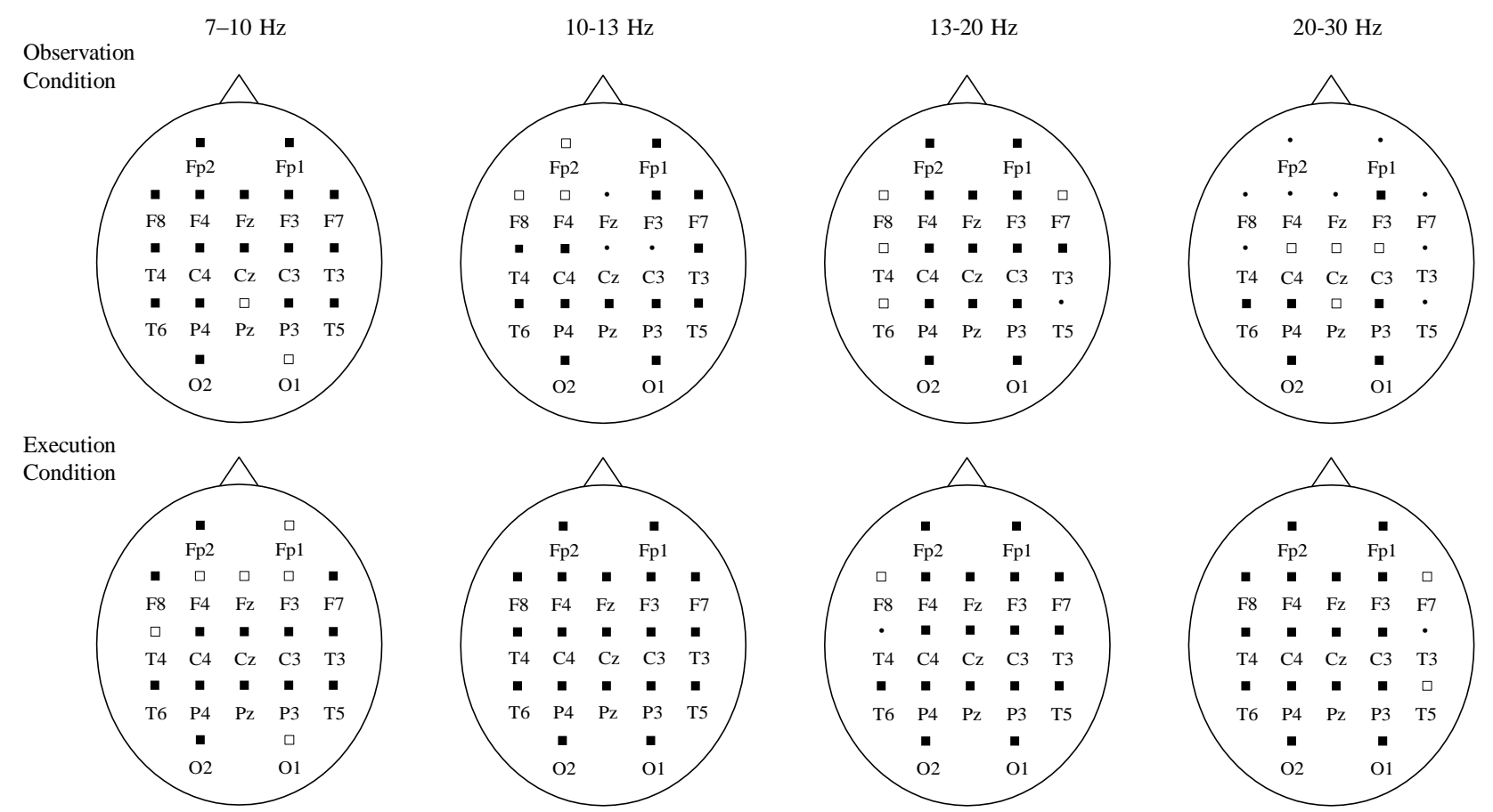

Figure 4. Schemas indicating the scalp locations that displayed significant differences in ERD/ERS power values in the pre-movement and movement stages. Dots $(\cdot)$ indicate electrode positions. $\bullet p<.0025$ (significant after Bonferroni correction). D .0025 $<p<.05$ (not significant after Bonferroni correction).

changes in EEG interchannel synchronization using the synchronization likelihood technique. This technique assesses global integration and synchronization of brain activity (Stam and van Dijk 2002). Data were collected prior to and during action execution and observation of the same action. They found, in $7-10 \mathrm{~Hz}, 10-13 \mathrm{~Hz}, 13-20$ $\mathrm{Hz}$, and $20-30 \mathrm{~Hz}$ frequency bands, no statistically significant differences in synchronization likelihood between the observation and execution data. This finding matches that found in this study for all frequency bands during the pre-movement and movement stages. Though no significant differences were found between observation and execution during the movement stage for all frequency bands, some trends towards significance were noted for the $10-13 \mathrm{~Hz}$ and $20-30 \mathrm{~Hz}$ bands. Under the execution condition, ERD values at some sites were greater than those under the observation condition, and for some particular $125 \mathrm{~ms}$ time periods. These findings are in agreement with those of Muthukumaraswamy and Johnson (2004) and Babiloni et al. (2002) for C3 and C4. The former research team examined scalp activity whilst participants performed a precision grip following its observation and during observation of the task alone. Their data showed a difference between observation and execution in the 10-12 Hz frequency band for a cluster of eight electrodes on each side of the scalp situated around C3 and C4. Babiloni et al. (2002) showed that right frontal ERD and bilateral central ERD showed higher amplitude during the execution condition than during the observation condition for the 8-12 Hz frequency band. In addition, central ERD showed greater amplitude during the movement execution in comparison to that for observation in the 14-27 Hz band.

Together, these results suggest that the mirror neuron system is involved during the observation of a sequential finger movement. No statistically significant differences in cortical activity were found between the observation condition and the execution condition. Interpretation should be made cautiously since lack of significant EEG activity difference detected between execution and observation does not imply equality. Differences between these two conditions may be related to deeper motor structures where activity is not present in scalp EEG (e.g., basal ganglia). Trends towards significance were also detected. In some frequency bands and for some electrodes, cortical markers seemed to be slightly different in the two conditions. We can suggest tentatively that a congruence between the observation and execution condition was not fully obtained. This difference could be due to the nature of the observed action. The activity of the observation-execution system appears to be modulated by the observation of a simple index flexion and extension. This is in accordance with Muthukumaraswamy and Johnson (2004) and Muthukumaraswamy et al. (2004). They have reported the sensitivity of the $8-13 \mathrm{~Hz}$ rhythm generated by the sensorimotor cortex to different forms of observed motor behaviors. These rhythms desynchronize during 
Table I. Pre-movement and movement ERD power values for each frequency band and electrode site under the observation and execution conditions

\begin{tabular}{|c|c|c|c|c|c|c|c|c|}
\hline & \multicolumn{2}{|c|}{ 7-10 (Hz) } & \multicolumn{2}{|c|}{ 10-13 (Hz) } & \multicolumn{2}{|c|}{$13-20(\mathrm{~Hz})$} & \multicolumn{2}{|c|}{$20-30(\mathrm{~Hz})$} \\
\hline & $\begin{array}{l}\text { premvt } \\
\text { ERD values }\end{array}$ & $\begin{array}{l}\text { mvt } \\
\text { ERD values }\end{array}$ & $\begin{array}{l}\text { premvt } \\
\text { ERD values }\end{array}$ & $\begin{array}{l}\text { mvt } \\
\text { ERD values }\end{array}$ & $\begin{array}{l}\text { premvt } \\
\text { ERD values }\end{array}$ & $\begin{array}{l}\text { mvt } \\
\text { ERD values }\end{array}$ & $\begin{array}{l}\text { premvt } \\
\text { ERD values }\end{array}$ & $\begin{array}{l}\text { mvt } \\
\text { ERD values }\end{array}$ \\
\hline \multicolumn{9}{|c|}{ Observation } \\
\hline FP2 & $-8,524$ & $-25,849$ & $-16,212$ & $-21,485$ & $-5,244$ & $-15,978$ & $-1,294$ & $-4,176$ \\
\hline FP1 & $-12,503$ & $-24,730$ & $-9,817$ & $-17,471$ & $-5,652$ & $-17,101$ & $-3,959$ & $-5,460$ \\
\hline F8 & $-6,389$ & $-16,450$ & $-19,654$ & $-26,465$ & $-10,218$ & $-15,982$ & $-7,522$ & $-6,677$ \\
\hline F7 & $-12,860$ & $-23,019$ & $-13,592$ & $-20,734$ & $-6,716$ & $-11,965$ & $-0,405$ & $-2,503$ \\
\hline $\mathrm{F} 4$ & $-5,893$ & $-25,235$ & $-19,944$ & $-23,219$ & $-10,072$ & $-22,251$ & $-1,556$ & $-4,539$ \\
\hline F3 & $-9,9594$ & $-26,140$ & $-9,447$ & $-16,476$ & $-11,394$ & $-22,216$ & $-1,620$ & $-7,580$ \\
\hline $\mathrm{T} 4$ & $-5,844$ & $-18,642$ & $-15,793$ & $-24,358$ & $-10,404$ & $-15,259$ & $-2,655$ & $-3,304$ \\
\hline T3 & $-0,638$ & $-16,042$ & $-14,399$ & $-21,773$ & $-6,730$ & $-13,157$ & 2,663 & 0,825 \\
\hline $\mathrm{C} 4$ & $-12,564$ & $-26,550$ & $-26,745$ & $-32,709$ & $-14,471$ & $-24,521$ & $-3,537$ & $-9,378$ \\
\hline $\mathrm{C} 3$ & $-13,999$ & $-28,952$ & $-21,5860$ & $-23,088$ & $-14,091$ & $-26,210$ & $-2,273$ & $-9,850$ \\
\hline T6 & $-11,499$ & $-27,584$ & $-17,808$ & $-28,022$ & $-15,733$ & $-20,394$ & $-6,100$ & $-12,423$ \\
\hline T5 & $-7,656$ & $-19,557$ & $-20,842$ & $-29,067$ & $-13,382$ & $-15,951$ & 4,967 & 1,621 \\
\hline $\mathrm{P} 4$ & $-22,777$ & $-37,459$ & $-28,668$ & $-46,408$ & $-19,304$ & $-29,366$ & $-5,480$ & $-13,746$ \\
\hline P3 & $-22,526$ & $-33,125$ & $-34,432$ & $-44,678$ & $-20,686$ & $-33,667$ & $-6,416$ & $-17,089$ \\
\hline $\mathrm{O} 2$ & -23 & $-33,848$ & $-36,621$ & $-56,070$ & $-19,122$ & $-34,040$ & $-10,488$ & $-23,070$ \\
\hline O1 & $-23,208$ & $-20,314$ & $-42,396$ & $-55,014$ & $-22,217$ & $-37,422$ & $-4,867$ & $-18,803$ \\
\hline FZ & $-10,679$ & $-28,999$ & $-11,984$ & $-14,356$ & $-11,561$ & $-22,379$ & $-2,769$ & $-6,053$ \\
\hline $\mathrm{CZ}$ & $-13,426$ & $-26,835$ & $-26,481$ & $-24,924$ & $-13,614$ & $-25,352$ & $-3,536$ & $-9,111$ \\
\hline PZ & $-18,484$ & $-30,953$ & $-30,253$ & $-43,727$ & $-16,532$ & $-29,098$ & $-5,579$ & $-14,228$ \\
\hline \multicolumn{9}{|c|}{ Execution } \\
\hline FP2 & $-11,524$ & $-23,976$ & $-21,821$ & $-37,562$ & $-7,888$ & $-24,172$ & $-4,002$ & $-16,030$ \\
\hline FP1 & $-14,459$ & $-23,762$ & $-21,581$ & $-42,136$ & $-10,705$ & $-21,388$ & $-8,692$ & $-16,400$ \\
\hline F8 & $-6,219$ & $-20,404$ & $-17,262$ & $-31,476$ & $-8,537$ & $-16,389$ & 0,417 & $-8,065$ \\
\hline F7 & 14,224 & $-15,823$ & $-12,589$ & $-31,176$ & $-1,073$ & $-11,786$ & $-5,355$ & $-11,814$ \\
\hline $\mathrm{F} 4$ & $-18,476$ & $-25,541$ & $-11,975$ & $-34,366$ & $-11,373$ & $-30,473$ & 1,033 & $-17,513$ \\
\hline F3 & $-21,068$ & $-26,193$ & $-19,022$ & $-42,577$ & $-16,428$ & $-30,578$ & $-9,338$ & $-22,406$ \\
\hline $\mathrm{T} 4$ & $-14,335$ & $-6,894$ & $-8,574$ & $-31,540$ & $-10,218$ & $-13,296$ & 2,348 & $-4,649$ \\
\hline T3 & 4,120 & $-27,205$ & $-16,511$ & $-37,108$ & $-12,953$ & $-26,157$ & $-6,036$ & $-5,593$ \\
\hline $\mathrm{C} 4$ & $-20,489$ & $-33,298$ & $-17,472$ & $-45,728$ & $-12,765$ & $-32,891$ & $-0,745$ & $-22,508$ \\
\hline C3 & $-21,828$ & $-31,403$ & $-19,551$ & $-49,639$ & $-11,872$ & $-32,964$ & $-8,610$ & $-26,264$ \\
\hline T6 & $-16,689$ & $-31,155$ & $-19,035$ & $-46,197$ & $-9,989$ & $-20,192$ & $-4,739$ & $-12,850$ \\
\hline $\mathrm{T} 5$ & 1,225 & $-28,059$ & $-22,410$ & $-34,937$ & $-11,979$ & $-19,289$ & $-3,488$ & 7,014 \\
\hline $\mathrm{P} 4$ & $-18,253$ & $-39,432$ & $-23,740$ & $-53,820$ & $-17,474$ & $-36,342$ & $-10,038$ & $-29,039$ \\
\hline P3 & $-22,014$ & $-37,601$ & $-23,113$ & $-53,504$ & $-12,364$ & $-33,734$ & $-4,144$ & $-21,942$ \\
\hline $\mathrm{O} 2$ & $-22,324$ & $-38,393$ & $-35,894$ & $-59,539$ & $-13,692$ & $-31,047$ & $-3,237$ & $-23,895$ \\
\hline O1 & $-22,669$ & $-29,391$ & $-36,750$ & $-54,561$ & $-4,517$ & $-31,301$ & 8,104 & $-10,004$ \\
\hline FZ & $-19,026$ & $-25,340$ & $-14,391$ & $-37,259$ & $-10,382$ & $-27,621$ & $-8,295$ & $-23,883$ \\
\hline $\mathrm{CZ}$ & $-21,137$ & $-29,146$ & $-16,064$ & $-43,393$ & $-10,053$ & $-28,969$ & $-5,095$ & $-21,196$ \\
\hline $\mathrm{PZ}$ & $-22,671$ & $-37,873$ & $-22,769$ & $-50,816$ & $-12,135$ & $-34,395$ & $-6,619$ & $-24,969$ \\
\hline
\end{tabular}

observation and, to a lesser extent, the observation of motorically-equivalent but non object-directed movement. Similarly, Buccino et al. (2001) showed that there is a different intensity in the activation of brain areas during the observation of object-related and non-objectrelated actions. Their results revealed that the parietal lobe was strongly involved during the observation of an object-directed action. This result is consistent with Iacoboni et al. $(1999,2001)$ and Koski et al. $(2002,2003)$ who noted reduced activation in the inferior parietal lobe when non-object-directed actions were observed. The variability of the mirror neuron system activity described can be explained by the characteristics of the observed action which are coded by the mirror system. During observation of non-object-related action, the participant may attend to movement details to make it more meaningful to himself or herself (Grèzes et al. 1998). Whereas, in actions oriented towards a goal, it is more likely that the individual focuses on the goal of the action. 


\section{Pre-movement and Movement Stages}

Significant differences in ERD/ERS power values between the pre-movement and movement stages were found at most of the scalp locations for the $7-10 \mathrm{~Hz}, 10$ $13 \mathrm{~Hz}, 13-20 \mathrm{~Hz}$ bands in the observation condition and for all the frequency bands in the execution condition. Pre-movement ERD values were lower than movement ERD values irrespective of condition. The first result, relating to the observation condition, cannot be discussed relative to previous research because, to our knowledge, no research has examined and compared ERD/ERS patterns of movement preparation and execution under an observation condition.

The results relating to the execution condition are consistent with the classical ERD/ERS literature (see Pfurtscheller and Lopes Da Silva 1999 for a review). Their data showed that changes in brain oscillations were associated with different stages of the movement. For voluntary self-paced finger movements, alpha-band synchronization was observed at $2.5 \mathrm{sec}$ before the onset of the movement. This activity occurred over the contralateral hemisphere to the movement and spread to the ipsilateral side immediately prior to the start of the movement. During movement execution, ERD of alpha-band activity developed symmetrically in the hemispheres. In contrast, beta desynchronization began approximately $1.5 \mathrm{sec}$ before movement onset and reached a maximum level before the end of the movement. This was followed by beta synchronization. The results of our study do not completely reflect this pattern. This difference could be explained by the nature of the task and that the EEG data in the present study were not transformed to referencefree data. Indeed, much of the research in this area has studied event-related power changes during brisk movement (e.g., Derambure, et al. 1999; Pfurtscheller et al. 1996; Pfurtscheller et al. 1998) and has used referencefree recordings (e.g., Muthukumaraswamy et al. 2004; Pfurtscheller et al. 2003).

Finally, a visual inspection of Fig. 4 shows that there is a congruence in the scalp locations, albeit partial, that displayed significant differences or trends towards significance, across the observation and execution conditions. This incomplete congruence could be attributed to the nature of the observed action as discussed previously and offers additional support for the existence of the mirror neuron system in humans.

\section{Limitations of the Study}

The present study may present two limitations. First, a measure of hand muscle activity during the two conditions was lacking. This was not conducted due to the properties of the EEG equipment used; its sampling rate was limited to $256 \mathrm{~Hz}$. Collecting electromyographic (EMG) data in this condition would have produced in- valid data. Indeed, according to the properties of the EMG signal (i.e., the power density function has a negligible contribution outside the range $5-10 \mathrm{~Hz}$ to $400-450$ Hz; Merletti and di Torino, 1999; International Society of Electrophysiology and Kinesiology, ISEK), a bandpass filter of $10-400 \mathrm{~Hz}$ should be used to collect EMG data. To be able to collect this, the minimal sampling rate employed should be at least $800 \mathrm{~Hz}$ as specified by the Nyquist theorem and preferably higher to improve accuracy and resolution (standards endorsed by the ISEK). In the present study, if hand EMG activity had been collected without following the ISEK standards, only part of the EMG signal (i.e., less than $25 \%$ of the EMG signal) would have been collected. In these conditions, it would have been difficult to determine accurately the onset of the movement or to have an objective measure of the muscle activity. Second, the choice of linked mastoids as the reference was not wholly appropriate, since it may produce a misrepresentation of the spatial components of the distribution over the scalp (Fisch and Pedley 1989). It may have been more advisable to transform the EEG data to reference-free data by using Laplacian operator methods (e.g., Hjorth 1975; Perrin et al. 1989) or the use of an average reference (Lehmann and Michel, 1989). These transformations were not completed in the present study because of the misleading results from a small number of recording channels (Babiloni et al. 1995, 1996; Dien 1998; Junghöfer et al. 1997; Yao et al. 2005). The reader is reminded that the choice of the reference electrode(s) and the adoption of a particular montage emphasize different properties of the EEG signals (Knyazeva et al. 1999; Pfurtscheller and Lopes da Silva 1988). For example, Pfurtscheller and Lopes da Silva (1988) have demonstrated that ERD was more widespread and extended over frontal areas using a monopolar and common average reference but was restricted to the occipital areas with Laplacians derivations during a reading task in the $8-12 \mathrm{~Hz}$ frequency band.

\section{Conclusion}

Whilst there did not seem to be an identical match of EEG cortical indicators between the observation and execution conditions, this study provides some additional support for the existence of a mirror neuron system in humans. This incomplete congruence may be explained by the nature of the task, a non-object-oriented action, and by some aspects of the observed action the mirror system codes.

\section{Acknowledgments}

The authors are grateful to the participants who participated in the study. They would also like to thank J-L. Bourriez for sharing his EEG knowledge, to A. Brossier 
and C. Debouzy for their knowledge in computer science and electronics, and to M. Paisley for the video footage editing.

\section{References}

Andres, F.G., Mima, T., Schulman, A.E., Dichgans, J., Hallett, M. and Gerloff, C. Functional coupling of human cortical sensorimotor areas during bimanual skill acquisition. Brain. 1999, 122: 855-870.

Babiloni, C., Babiloni, F., Carducci, F., Fattorini, L., Onorati, P. and Urbano, A. Performances of surface Laplacian estimators: A study of simulated and real scalp potential distributions. Brain Topogr. 1995, 8: 35-45.

Babiloni, C., Babiloni, F., Carducci, F., Fattorini, L., Onorati, P. and Urbano, A. Spline Laplacian estimate of EEG potentials over a realistic magnetic resonance-constructed scalp surface modelElectroencephalogr. Clin. Neurophysiol. 1996, 98: 363-373

Babiloni, C., Babiloni, F., Carducci, F., Cincotti, F., Cocozza, G., Del Percio, C., Moretti, D.V. and Rossini, P.M. Human cortical electroencephalography (EEG) rhythms during the observation of simple aimless movements: A high-resolution EEG study. Neuroimage. 2002, 17: 559-572.

Blinowska, K.J. and Durka, P.J. Unbiased high resolution method of EEG analysis in time-frequency space. Acta Neurobiol. Exp. 2001, 61: 157-174.

Buccino, G., Binkofski, F., Fink, G.R., Fadiga, L., Fogassi, L., Gallese, V., Seitz, R.J., Zilles, K., Rizzolatti, G. and Freund, H.J. Action observation activates premotor and parietal areas in a somatotopic manner: An fMRI study. Eur. J. Neurosci. 2001, 13: 400-404.

Buccino, G., Binkofski, F. and Riggio, L. The mirror neuron system and action recognition. Brain Lang. 2004a, 89:370376.

Buccino, G., Lui, F., Canessa, N., Patteri, I., Lagravinese, G., Benuzzi, N., Porro, C.A. and Rizzolatti, G. Neural circuits involved in the recognition of actions performed by nonspecifics: An fMRI study. J. Cogn. Neurosci. 2004b, 16: 114-126.

Burgess, A.P. and Gruzelier, J.H. Methodological advances in the analysis of event-related desynchronization data: Reliability and robust analysis. In: G. Pfurtscheller and F.H. Lopes da Silva (Eds.), Handbook of electroencephalography and clinical neurophysiology. Revised series, vol. 6 . Elsevier Science, Amsterdam. 1999: 139-158.

Calmels, C., Holmes, P., Jarry, G., Hars, M., Lopez, E., Paillard, A. and Stam, C.J. Variability of EEG synchronization prior to, and during, observation and execution of a sequential finger movement. Hum. Brain. Mapp. 2006, 27: 251266.

Classen, J., Gerloff, C., Honda, M. and Hallett, M. Integrative visuomotor behavior is associated with interregionally coherent oscillations in the human brain. J. Neurophysiol. 1998, 79: 1567-1573.

Cochin, S., Bathelemy, C., Roux, S. and Martineau, J. Observation and execution of movement: Similarities demonstrated by quantified electroencephalography. Eur. J. Neurosci. 1999, 11: 1839-1842.
Derambure, P., Defebvre, L., Bourriez, J.L., Cassim, F. and Guieu, J.D. Désynchronisation et synchronisation liées à l'événement. Etude de la réactivité des rythmes électrocorticaux en relation avec la planification et l'exécution du mouvement volontaire [Event-related desynchronisation and synchronization. Reactivity of cortical electroencephalographic rhythms related to planning and performance of voluntary movement]. Neurophysiol. Clin. 1999, 29: 53-70.

Dien, J. Issues in the application of the average reference: Review, critiques, and recommendations. Behav. Res. Methods Instrum. Comput. 1998, 30: 34-43.

Duhamel, P. and Vetterli, M. Fast Fourier transforms: A tutorial review and a state of the art. Signal Process. 1990, 19: 259_ 299.

Fadiga, L., Fogassi, L., Pavesi, G. and Rizzolatti, G. Motor facilitation during action observation: A magnetic stimulation study. J. Neurophysiol. 1995, 73: 2608-2611.

Fisch, B.J. and Pedley, T.A. The role of quantitative topographic mapping or 'neurometrics' in the diagnosis of psychiatric and neurological disorders: The cons. Electroencephalogr. Clin. Neurophysiol. 1989, 73: 5-9.

Gallese, V., Fadiga, L., Fogassi, L. and Rizzolatti, G. Action recognition in the premotor cortex. Brain. 1996, 119: 593609.

Gerloff, C. and Hallett, M. ERD and coherence of sequential movements and motor learning. In: G. Pfurtscheller and F.H. Lopes da Silva (Eds.), Handbook of electroencephalography and clinical neurophysiology. Revised series, vol. 6. Elsevier Science, Amsterdam. 1999: 327-339.

Grèzes, J., Costes, N. and Decety, J. Top-down effect of strategy on the perception of human biological motion: A PET investigation. Cogn. Neuropsychol. 1998, 15: 553-582.

Hjorth, B. An on line transformation of EEG scalp potentials into orthogonal source derivations. Electroenceph. Clin. Neurophysiol. 1975, 39: 526-530.

Iacoboni, M., Koski, L.M., Brass, M., Bekkering, H., Woods, R.P. Dubeau, M.C., Mazziotta, J.C. and Rizzolatti, G. Reafferent copies of imitated actions in the right superior temporal cortex. Proc. Natl. Acad. Sci. USA. 2001, 98: 13995-13999.

Iacoboni, M., Woods, R.P., Brass, M., Bekkering, H. and Mazziotta, J.C. Cortical mechanisms of human imitation. Science. 1999, 286: 2526-2528.

Jackson, P.L., Meltzoff, A.N. and Decety, J. Neural circuits involved in imitation and perspective-taking. NeuroImage. 2006, 31: 429-439.

Jasper, H.H. Report of the committee on methods of clinical examination in electroencephalography. Electroenceph. Clin. Neurophysiol. 1958, 10: 370-375.

Junghöfer, M., Elbert, T., Leiderer, P. et al. Mapping EEGpotentials on the surface of the brain: A strategy for uncovering cortical sources. Brain Topogr. 1997, 9: 203217.

Kilner, J.M., Vargas, C., Duval, S., Blakemore, S.J. and Sirigu, A. Motor activation prior to observation of a predicted movement. Nat. Neurosci. 2004, 7: 1299-1301.

Knyazeva, M.G., Kiper, D.C., Vilvadski, V.Y., Despland, P.A., Maeder-Ingvar, M. and Innocenti, G.M. Visual stimulusdependent changes in interhemispheric EEG coherence in humans. J. Neurophysiol. 1999, 82: 3095-3107. 
Koski, L., Iacoboni, M., Dubeau, M.C., Woods, R.P. and Mazziotta, J.C. Modulation of cortical activity during different imitative behaviors. J. Neurophysiol. 2003, 89: 460471.

Koski, L., Wohlschlager, A., Bekkering, H., Woods, R.P. and Dubeau, M.C. Modulation of motor and premotor activity during imitation of target-directed actions. Cereb. Cortex. 2002, 12: 847-855.

Lehmann, D. and Michel, M.E. Intercerebral dipole sources of EEG FFT power maps. Brain Topograph. 1989, 2: 155-164.

Maeda, F., Kleiner-Fisman, G. and Pascual-Leone, A. Motor facilitation while observing hand actions: Specificity of the effect and role of observer's orientation. J. Neurophysiol. 2002, 87: 1329-1335.

Makuuchi, M. Is broca's area crucial for imitation. Cereb. Cortex. 2005,15: 563-570.

Manganotti, P., Gerloff, C., Toro, C., Katsuta, H., Sadato, N., Zhuang, P., Leocani, L. and Hallett, M. Task-related coherence and task-related spectral power changes during sequential finger movements. Electroenceph. Clin. Neurophysiol. 1998, 109: 50-62.

Merletti, R. and di Torino, P.Standards for reporting EMG data. J. Electromyogr. Kines. 1999, 9: III-IV.

Muthukumaraswamy, S.D. and Johnson, B.W. Changes in rolandic mu rhythm during observation of a precision grip. Psychophysiology. 2004, 41: 152-156.

Muthukumaraswamy, S.D., Johnson, B.W. and McNair, N.A. $\mathrm{Mu}$ rhythm modulation during observation of an objectdirected grasp. Cogn. Brain Res. 2004, 19: 195-201.

Oldfield, R.C. The assessment and analysis of handedness: The Edinburgh Inventory. Neuropsychologia. 1971, 9: 97-113.

Patuzzo, S., Fiaschi, A. and Manganotti, P. Modulation of motor cortex excitability in the left hemisphere during action observation: A single- and paired-pulse transcranial magnetic stimulation study of self- and non-self-action observation. Neuropsychologia. 2003, 41: 1272-1278.

Perani, D., Fazio, F., Borghese, N.A., Tettamanti, M., Ferrari, S., Decety, J. and Gilardi, M.C. Different brain correlates for watching real and virtual hand actions. NeuroImage. 2001, 14: 749-758.

Perrin, F., Pernier, J., Bertrand, O. et al. Spherical splines for scalp potential and current density mapping. Electroenceph. Clin. Neurophysiol. 1989, 72: 184-187.

Pfurtscheller, G. and Aranibar, A. Event-related cortical desynchronization detected by power measurement of scalp EEG. Electroenceph. Clin. Neurophysiol. 1977, 42: 817826.

Pfurtscheller, G. and Lopes da Silva, F.H. Functional brain imaging. Hans Huber, Toranto. 1988.

Pfurtscheller, G. and Lopes da Silva, F.H. Event-related desynchronization. Handbook of Electroencephalography and clinical neurophysiology. Revised series, Vol. 6. Elsevier, Amsterdam. 1999: 406.

Pfurtscheller, G., Stancak, A. and Neuper, C. Post-movement beta synchronization. A correlate of an idling motor area? Electroenceph. Clin. Neurophysiol. 1996, 98: 281-293.
Pfurtscheller, G., Woertz, M., Supp, G. and Lopes da Silva, F.H. Early onset of post-movement beta electroencepalogram synchronization in the supplementary motor area during self-paced finger movement in human. Neurosci. Lett. 2003, 339: 111-114.

Pfurtscheller, G., Zalaudek, K. and Neuper, C. Event-related beta synchronization after wrist, finger and thumb movement. Electroenceph. Clin. Neurophysiol. 1998, 109: 154160.

Rizzolatti, G. The mirror neuron system and its function in humans. Anat. Embryol. 2005, 210: 419-421.

Rizzolatti, G., Carmada, R., Fogassi, L., Gentilucci, M., Luppino, G. and Matelli, M. Functional organization of inferior area 6 in the macaque monkey: II. Area F5 and the control of distal movements. Exp. Brain Res. 1988, 71: 491-507.

Rizzolatti, G. and Craighero, L. The mirror-neuron system. Annu. Rev. Neurosci. 2004, 27: 169-192.

Rizzolatti, G., Fogassi, L. and Gallese, V. Neurophysiological mechanisms underlying the understanding and imitation of action. Nat. Rev. Neurosci. 2001, 2: 661-670.

Stam, C.J. and van Dijk, B.W. Synchronization likehood: An unbiased measure of generalized synchronization in multivariate data sets. Physica. D. 2002, 163: 236251.

Sterman, M.B., Mann, C.A., Kaiser, D.A. and Suyenobu, B.Y. Multiband topographic EEG analysis of a simulated visuomotor aviation task. Int. J. Psychophysiol. 1994, 16: 49-56.

Stevens, J.A., Fonlupt, P., Shiffrar, M. and Decety, J. New aspects of motion perception: Selective neural encoding of apparent human movements. Neuroreport. 2000, 11: 109115.

Tai, Y.F., Sherfler, C., Brooks, D.J., Sawamoto, N. and Castiello, U. The human premotor cortex is 'mirror' only for biological actions. Curr. Biol. 2004, 14: 117-120.

Varela, F., Lachaux, J.-P., Rodriguez, E., Martinerie, J. The brain web: Phase synchronization and large-scale integration. Nature Rev. Neurosci. 2001, 2: 229-239.

Weiss, S. and Rappelsberger, P. Long-range EEG synchronization during word encoding correlates with successful memory performance. Cognitive Brain Res. 2000, 9: 299312.

Yao, D., Wang, L., Oostenveld, R., Nielsen, K.D., ArendtNielsen, L. and Chen, A.C.N. A comparative study of different references for EEG spectral mapping: The issue of the neutral reference and the use of the infinity reference. Physiol. Meas. 2005, 26: 173-184.

Zhang, J.X., Feng, C.M., Fox, P.T., Gao, J.H. and Tan, L.H. Is left inferior frontal gyrus a general mechanism for selection? NeuroImage. 2004, 23: 281-287.

Zhuang, P., Toro, C., Grafman, J., Manganotti, P., Leocani, L., and Hallet, M. Event related desynchronization (ERD) in alpha frequency during development of implicit and explicit learning. Electroenceph. Clin. Neurophysiol. 1997, 102: 374-381. 